\title{
A COMPARATIVE STUDY BETWEEN DYNAMIC HIP SCREW AND PRIMARY HEMIARTHROPLASTY IN TROCHANTERIC FRACTURE OF FEMUR IN ELDERY
}

Prasanta Kumar Mandal, Dibakar Ray, Mrinal Kanti Ray, Fagu Ram Majhi, Somnath Tirkey, Amalendu Bikash Chatterjee

1. Associate Professor. Department of Orthopaedics, Bankura Sammilani Medical College \& Hospital.

2. Assistant Professor. Department of Orthopaedics, Bankura Sammilani Medical College \& Hospital.

3. Assistant Professor. Department of Orthopaedics, Bankura Sammilani Medical College \& Hospital.

4. Assistant Professor. Department of Orthopaedics, Bankura Sammilani Medical College \& Hospital.

5. Junior Resident, Department of Orthopaedics, Bankura Sammilani Medical College \& Hospital.

6. Associate Professor. Department of Anaesthesia, Bankura Sammilani Medical College \& Hospital.

\section{CORRESPONDING AUTHOR}

Dr. Prasanta Kumar Mandal,

Vill. Lokepur, P.O. Kenduadihi,

Bankura- 722102.

E-mail: drprasantamondal@gmail.com

Ph: 00919434173124.

ABSTRACT: Hip fractures, particularly in older persons, result in problems that extend far beyond the orthopedic injury, with repercussions in the areas of medicine, rehabilitation, psychiatry, social work, and health care economics. The degree of osteoporosis may influence fracture type. For these reasons, the treatment of intertrochanteric fractures is operative.

Our propose of the study to compare the result of dynamic hip screw fixation and hemiarthroplasty in intertrochanteric fractures of hip in elderly. This study has used Harris Hip Score to compare and evaluate the functional outcome.

KEY WORDS: hemiarthroplasty, intertrochanteric fractures, of dynamic hip screw fixation

INTRODUCTION: Hip fractures are among the most common injuries in the elderly. The impact of these injuries goes far beyond immediate clinical considerations and extends into the domains of medicine, rehabilitation, psychiatry, social work and medical economics. The challenge in treating geriatric hip fracture is further compounded by their growing members in the face of continually increasing pressures for health care cost containment.. The incidence increases with age, doubling for each decade after 50 years, and is two to three times higher in women than in men ${ }^{1}$. Intertrochanteric femoral fractures have been estimated to occur in more than 200000patients each year in the united state with reported mortality rate ranging from $15 \%$ to $30 \%$.(2)

The degree of osteoporosis may influence fracture type. Lawton ${ }^{3}$ et al reported that intertrochanteric hip fractures and that they had lower hemoglobin levels at hospital admission, poorer prefracture ambulatory ability and higher number of associated medical conditions that affected fracture management.

Patients with intertrochanteric fractures are significantly older, more likely to be limited to home ambulation, and more dependant in their activities of daily living, therefore, they tend to have an overall poorer prognosis.

Before the introduction of suitable fixation devices, treatment of intertrochanteric fractures was nonoperative, consisting of prolonged bed rest in traction until fracture healing 
occurred (usually 10 - 12 weeks ), followed by a lengthy programme of ambulation training . In elderly patients, this approach was associated with high complication rates; typical problems included decubitus ulcers, urinary tract infection, Joint contractures, Pneumonia and thromboembolic complications, resulting in a high mortality rate. In addition, fracture healing was generally accompanied by varus deformity and shortening because of the inability of traction to effectively counteracts the deforming muscular forces. By operative management we can hopefully prevent above complication.

For these reasons, the treatment of intertrochanteric fractures is operative.

METHODS AND MATERIALS: Between July 2010 and 2013 august 36 patients were taken in this study at our institute (BANKURA SAMMILANI MEDICAL COLLEGE) for fracture trochanteric fracture of femur in elderly above 60 years of both sex 12 patents were male and 18 patients were female 6 patients in lost follow up 15 patients were operated by dynamic hip screw fixation and 15 patients by hemiarthroplasty. The patients were follow up at interval of 3 months, 6 months, 12 months and yearly. The patents were evaluated by Harris Hip score.. The mean days of hospitalization in Haentjens reference ${ }^{16}$, P et al study.. The bed occupancy was increased mainly due to operative delay while the post operative hospital was relatively shorter. The minimum age of the point in our study was 65 years and maximum up to 101 years with mean age of 76.4 years. People of this age group have osteoporosis and yet they are ambulatory that is why patient of this age group have more case of it. After the age of 84 years most of them are either no ambulatory or assisted ambulatory. So they are less exposed to traumatic event of fall. This explains the decreased rate of it over 84 years. Finding of this study are comparable to the studies done by Haentjens, $P$ reference ${ }^{16}$ et al whose mean age was 82 years

As far as sex distribution is concerned we also find females are more predominant i.e female ratio of $1: 1.5$. The mean age of female was 76.39. Post menopausal osteoporosis is most likely the cause of higher incident in female.. In Haentjens reference ${ }^{16}$, P et al study there was 8 males \& 29 females with M:F ratio of 1:3:5. . Majority of the cases had one or the other comorbid disease. The 23 patients (76\%) had 26 co- morbidities while 7 patients were free from comorbid diseases. Cardiovascular diseases were the predominant cause with 10 patients having hypertensive heart disease seven patient had chronic obstructive pulmonary diseases. One patient had Parkinsonism one had Osteoarthritis of knee, one patient was blind, one had post TB lung fibrosis and one was diabetic and had CRF. All these diseases are common in elderly population of our country and they have a significant impact on post injury functional outcome, hence patient need to be ambulated as early as possible, so as to recover from ensuing complications. Our findings were corroborated by other studies. In Haentjens ${ }^{16}$, P et al study, $76 \%$ of patients had co-morbid diseases

In our study involvement of the right side (53.3\%) was more common than the left side (46.7\%)... When grouped in terms of stability half (50\%) of the fracture patterns were unstable. This result further emphasizes that $50 \%$ of all pertrochanteric fractures are unstable, hence needs a device which provide stability and allow early ambulation. Hemiarthroplasty can provide this opportunity Clinical and radiological follow up was done at 3 months, 6 months, 12 months and yearly.

RESULTS: Thirty six patients with peritrochanteric fractures were included in this study. Six patients did not met the requirement of 6 monthes follow- up so they were excluded from the final analysis. In the final analysis only 30 patients were entered. The results and observations 
are as follows 15 patients type II, 5 patients type III, 1 patient type IV where are the rest 9 patients type 1

When grouped in terms of stability half $(50 \%)$ of the fracture patterns were unstable. This result further emphasizes that $50 \%$ of all peritrochanteric fractures are unstable, hence needs a device which provide stability and allow early ambulation. Hemiarthroplasty can provide this opportunity. Our result are consistent with other studies. In Haentjens ${ }^{16}, \mathrm{P}$ et al study all fracture patterns undergoing bipolar hemiarthroplasty were unstable. As far as complications are concerned, out of 30 patients who were followed up for complete 6 months ( 6 out of 36 dropped out in follow up), . Among the 14 patient, 4 (13.3\%) patients superficial wound infection; two patients had limb length discrepancy more than $2 \mathrm{~cm}$. One patient sustained prosthesis hip dislocation on $7^{\text {th }}$ post operative day after a fall in toilet which was reduced by closed means and managed with traction for three weeks. One patient had per operative fracture of greater trochanter, which had to be fixed with tension band wiring.

DISCUSSION: The treatment of unstable intertrochantric and subtrochantric fractures in elderly patients is still controversial. Elderly patients, even if they are in good general healthy, cannot usually be mobilized without some weight being borne on the involved limb. This has led to the design of several types of devices for internal fixation. No single implant, however, is universally accepted for the operative treatment of these fractures, and new fixation devices are introduced periodically. The dynamic devices- popularized as a sliding screw/side plate, sliding nail, telescoping nail, dynamic hip screw, and sliding hip screw - are currently in wide use as reliable methods of internal fixation ${ }^{4}$, although the operative technique is not always easy and postoperative regimens cannot be standardized.

Fracture fixation with a sliding hip- screw device proved to be an improvement compared to fixed blade plates and Enders nails. However, even with this device, early full weight bearing mobilization of unstable fracture can result in rotational deformity and leg length shortening due to uncontrolled telescoping and screw Cut outs .Elderly especially debilitated patient in need of early mobilization pose many problems. For these reasons the insertion of an endoprosthesis is elected for patient with osteoporosis complicated by a unstable fracture. With this treatment, immediate postoperative full weight bearing mobilization is allowed.

Some authors argue that by using prosthesis arthroplasty instead of internal fixation in certain unstable intertrochanteric fracture, one potential set of problems associated with prosthesis (dislocation, limb length discrepancy) has merely been trade for another set associated with internal fixation, hardware "cutting out"). However, using as a guide, the fascial fibres between the greater trochanter and upper femoral shaft have overcome the limb-length discrepancy problem. Moreover, preserving the hip capsule using purse-string type closure may enhance hip stability. With these technical considerations in mind, head-neck cemented prosthesis arthroplasty for unstable intertrochanteric fractures in forgetful, elderly patients may be a suitable alternative to internal fixation because the prosthesis provides for early full weight-bearing and rapid rehabilitation.

The post-op complication in Haentjens ${ }^{16}$, P et al study was $13 \%$. It was significantly increased when compared to Haentjens, $\mathrm{P}$ et al study

When compared to I hip dislocation in our study, Haentjens ${ }^{16}, \mathrm{P}$ et al study had 2 incidents,. The findining is increased compared to Haentjens, P et al study 
The mean Harris hip score increased progressively during consecutive follow up. The mean score was 46.5 at third day, which increase to 59.9 by seven day. At two weeks the score was 72.8 while at I and 3 month. The scores were 79.2 and 82.8 respectively. The final Harris hip screw hip score at last follow up was 86.

At third post op day the score was poor. From third to seventh day $83.3 \%$ has poor score, while rest had fair scoring. By two weeks majority had fair scoring. At one month, score was good in half of the cases and fair in $40 \%$ and poor in the rest. At 3 month, Harris hip score was good in $3 / 4^{\text {th }}$ of the cases and excellent in $6.7 \%$ while fair in remaining $16.7 \%$. At last follow up score was fair in $10 \%$ good in $60 \%$ and excellent in remaining $40 \%$ of the cases. Thus we see that the score has increased progressively and the difference in score between consecutive two follow-ups is highly significant.

By 6 months $90 \%$ of our patients capable of independent ambulation whereas the percentage of independent ambulation at 6 months in Haentjens ${ }^{16}$, P et al study was $79 \%$ ( $p$ value 0.34 ),

The mortality in Haentjens ${ }^{16}$, $\mathrm{P}$ et al study, $35 \%$. In our study there was no mortality till 6 months. We could not trace the patients who dropped out in follow-up. The reason might be that our mean age was less than other study group, shorter follow-up period \& strict physiotherapy protocol.

As a matter of fact, internal fixation is the most commonly done operation for intertrochanteric fractures. So, it's imperative that we compare our result with them. Haentjens ${ }^{16}$, P et al had compared the result of bipolar hemiarthroplasty with osteosynthesis, so we compared our result with theirs.

In all the parameters, except follow-up period and mortality rate, our result were comparable with those of Haentjens, $\mathrm{P}$ et al study for easy understanding. The finding are tabulated below.

Unstable intertrochanteric fractures are histrorically associated with a high rate of complication ${ }^{5}$. Immediate partial or full weight-bearing in this patiets group is crucial - though not always possible - after internal fixation with dynamic hip screw or proximal femoral nails. Cutting-out of these hip screw has been reported in $4 \%-20 \%$ of cases ${ }^{5}$. Primary total hip replacement has been considered a viable option in a select group of previously independent mobile patients and is reported to be associated with significantly lower complication rates ${ }^{5}$.

The presence of four or more comorbidities has been shown to increase the risk of death by approximately $78 \%{ }^{6,7}$. Rodop et $\mathrm{al}^{8}$ published a study on standard hemiarthroplasty for the treatment of displaced intertrochanteric fracture in a small group of 54 elderly patients, they reported good functional result in terms of walking ability of there patients. Similarly Haentjens et $\mathrm{al}^{9}$. Found better functional outcome and reduced morbidity (pressure sores, pulmonary infection and atelectasis) with arthroplasty, but mortality rates were not reduced ${ }^{9}$. Cemented prostheses have been used routinely and these usually provide immediate stability and permit full weight-bearing10,11.

Kim et al ${ }^{12}$ compared the 2-years results of long stem cementsless calcar replacement hemiarthroplasty with the results after proximal femoral nail for unstable intertrochanteric fracture in 58 elderly patients. A superior clinical outcome was seen with proximal femoral nails. However there was no advantage in functional outcome compared to arthroplasty group ${ }^{12}$. Dislocation has been a major complication with total hip replacement after comminuted intertrochanteric fractures and bipolar arthroplasty has been shown to reduced this risk. 
Primary cemented arthroplasty for intertrochanteric fractures is technically challenging. In severely comminuted fractures restoration of limb rotation and length can be demanding.

The debate then shifts to whether cementless hip arthroplasty in the very elderly is successful or not, given the possible complications noted with improper technique. Uniformly good results have been reported with cementless total hip arthroplasty in the very elderly population $13,14,15$. Some studies have been shown less operating time and blood loss for the uncemented cohorts ${ }^{15}$ with no worse postoperative mortality or complication rates.

\section{REFERENCES:}

1. Cummings SR, Kelsey JL, Nevitt MC, O’Dowd KJ. Epidemiology of osteoporosis and osteoporotic fractures. Epidemiol Rev 7:178-208, 1985.

2. Campbell's Operative Orthopedics $11^{\text {th }}$ edn Page no 3239.

3. Lawton JO, Baker MR, Dickson RA. Femoral neck fractures: two populations. Lancet, 2:70-72, 1983.

4. Kenzora, J. E, McCarthy, R. E. Lowell, J.D. And Sledge, C.B. Hip fracture mortality. Relation to age, treatment, preperative illness, time of surgery, and complication. Clin. Orthop , 186:45-56, 1984.

5. Geiger F, Zimmermann-Stenzel M, Heisel C, Lehner B, Daecke W. trochanteric fractures in the elderly: The influence of primary hip arthroplasty on 1-years morality. Arch Orthop Trauma Surg 2007;127:959-66.

6. Bezwada HP, Shah AR, Harding SH, Baker J, Johanson NA, Mont MA, Cementless bipolar hemiarthroplasty for displaced femoral neck fractures in the elderly. J Arthroplasty 2004;19:73-7.

7. Lu-Yao GL, Baron JA, Barrett JA, Fisher ES. Treatment and survival among elderly Americans with hip fractures: A population-based study. Am J Public Health 1994;84:1287-91.

8. Rodop O, Kiral A, Kaplan H, Akmaz I. Primary bipolar hemiprosthesis for unstable intertrochanteric fractures. Int Orthop 2002;26:233-7.

9. Haentjens P, Casteleyn PP, Opdecam P. Primary bipolar arthroplasty or total hip arthroplasty for the treatment of unstable intertrochanteric and subtrochanteric fractures in elderly patients, Acta Orthop Belg 1994;60:124-8.

10. Parvizi J, Holiday AD, Ereath MH, Lewallen DG. Sudden death during primary hip arthroplasty. Clin Orthop Relat Res 1999;369:39-48.

11. Donaldson AJ, Thomson HE, Harper NJ, Kenny NW. Bone cement implantation syndrome. Br J Anaesth 2009;102:12-22.

12. Kim SY, Kim YG, Hwang JK, Cementless calcar-replacement hemiarthroplasty compared with intramedullary fixation of unstable intertrochanteric fractures. A prospective, randomized study. J bone Joint Surg Am 2005;87:2186-92.

13. Kostantoulakis C, Anastopolos G, Papaeliou A, Tsoutsanis A, Asimakopoulus A. Uncemented total hip arthroplasty in the elderly. Int Orthop 1999;23:334-6.

14. Ahn J, Man LX, Park S, Sodl JF, Esterhai JL. Systematic review of cemented and uncemented hemiarthroplasty outcomes for femoral neck fractures. Clin Orhop Relat Res 2008;466:2513-8.

15. Ozturkmen Y, Karamehmetoglu M, Caniklioglu M, Ince Y, Azboy Y. Cementless hemiarthroplasty for femoral neck fractures in elderly patients. Indian J Orthop 2008;42:56-60. 
16. Haentijens P. Casteleyn PP, Boeck HD, Handelberg F, Opdecam P. Treatment of Unstable Intertrochanteric and Subtrochanteric Fractures in Elderly Patients. The Journal of Bone and Joint Surg, 71-A, 8, Sep 1989.

Table : Comparision of the series with internal fixation

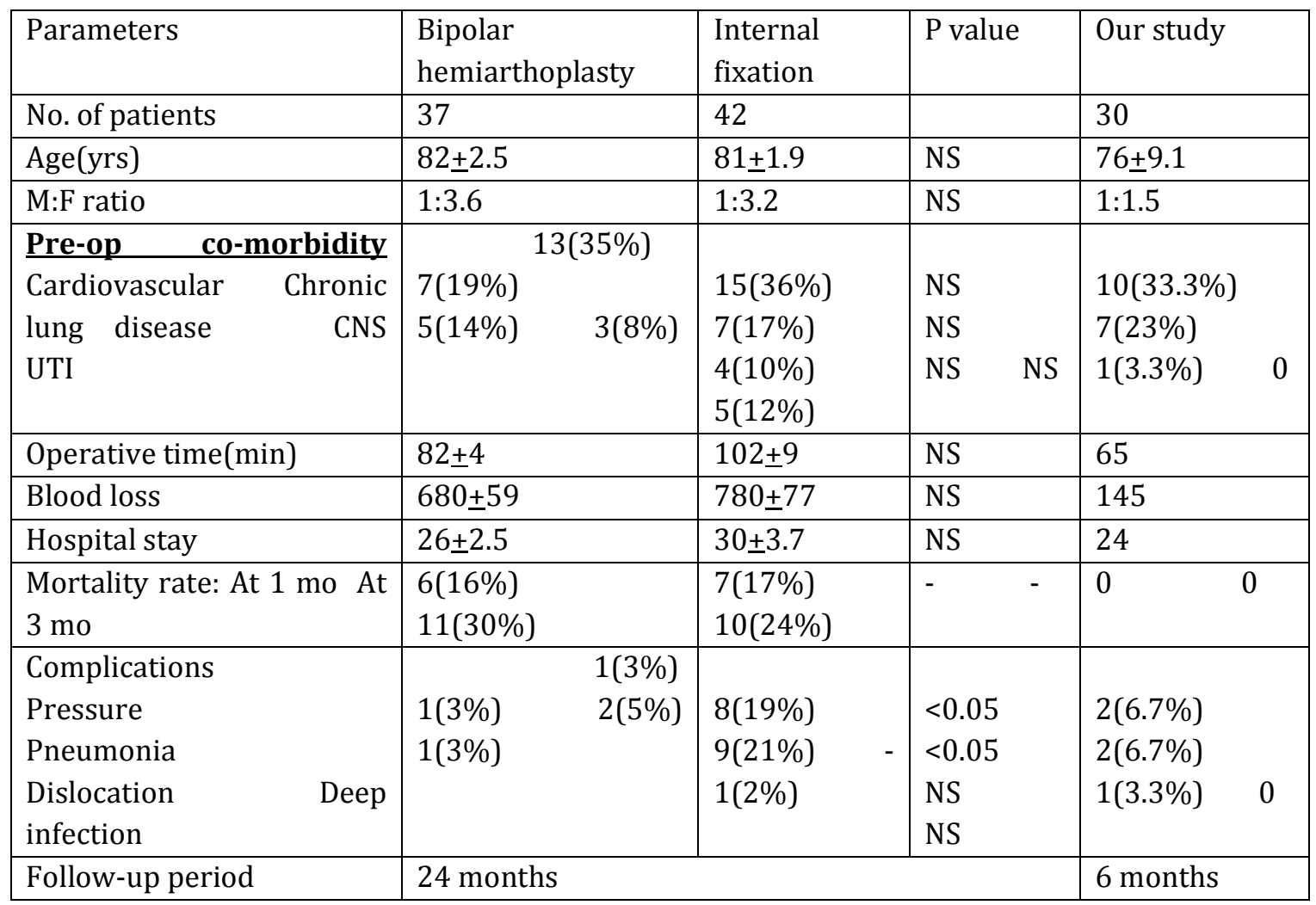




\section{ORIGINAL ARTICLE}

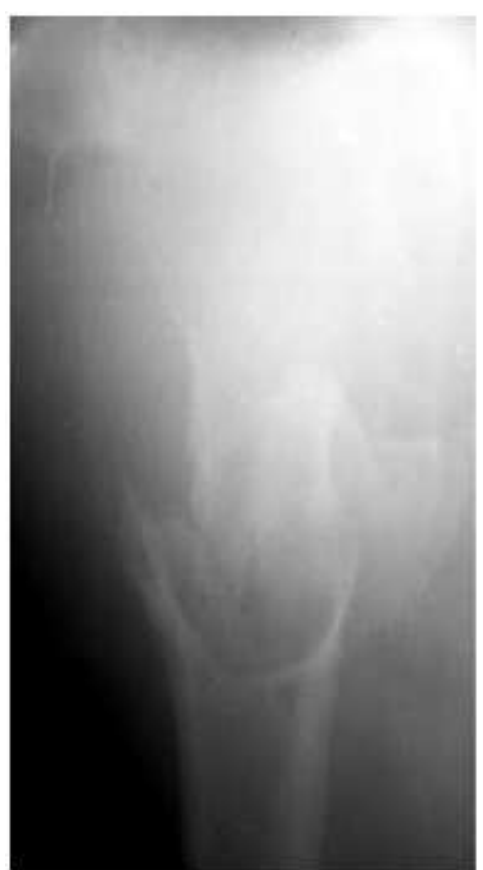

Fig 1 Pre of lat view of Lt hip

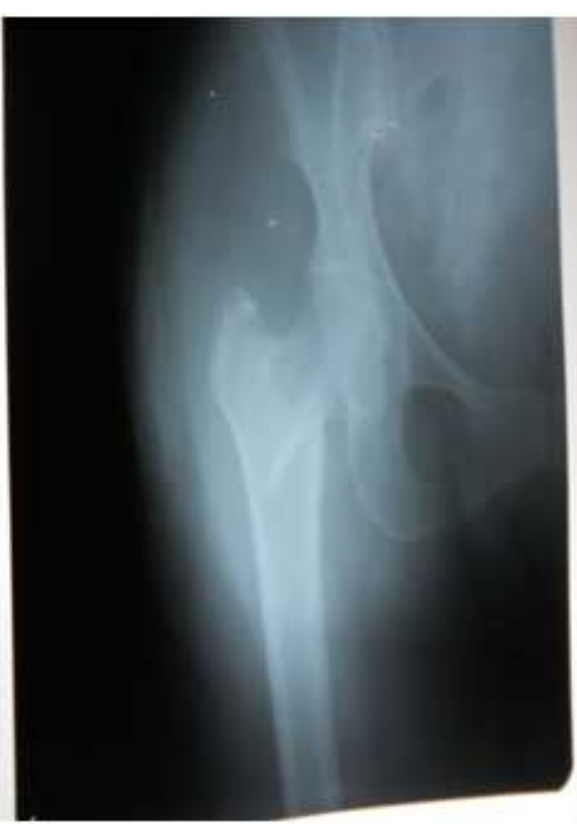

Fig 3 Pre of AP view (Rt Hip)

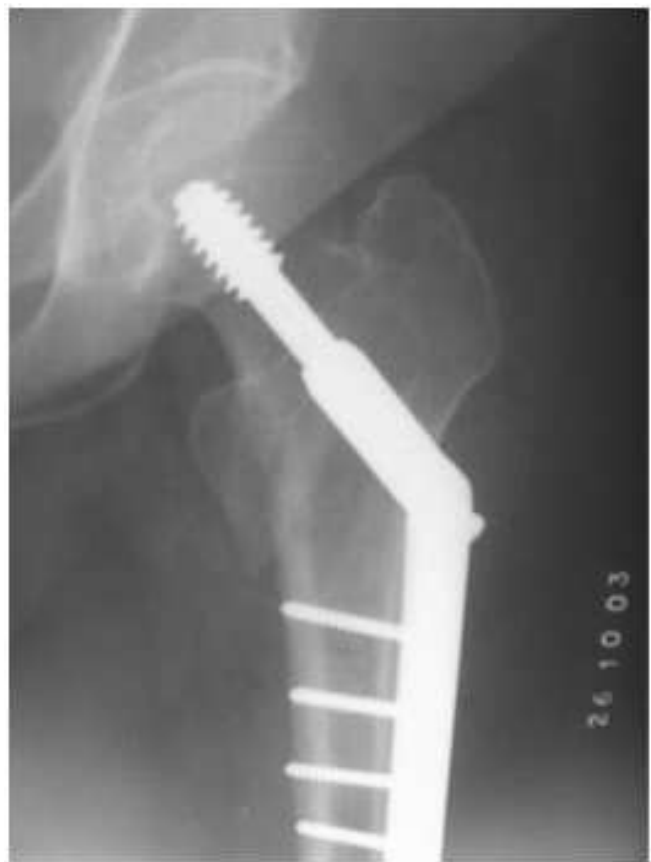

Fig 2 Post of AP view

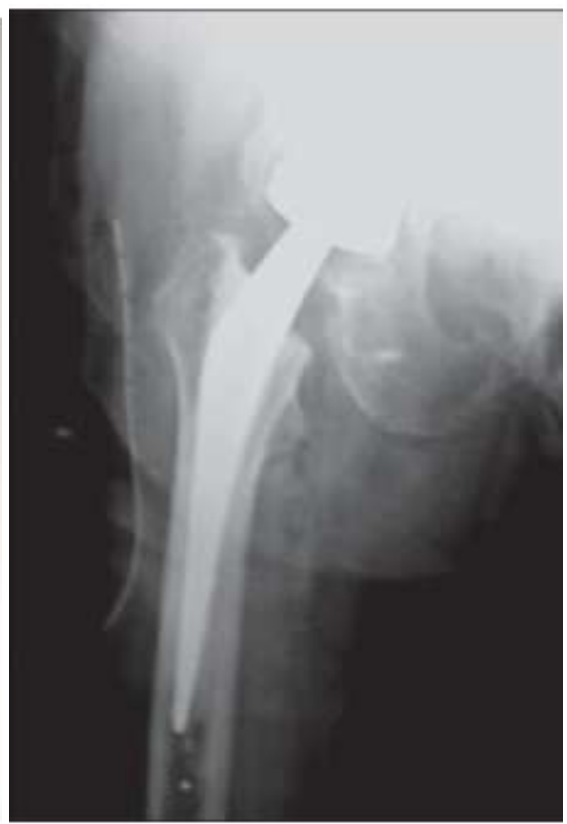

Fig 4 Post of cemented bipolar prosthesis 